\title{
Electrospun nanosized cellulose fibers using ionic liquids at room temperature $\dagger$
}

\author{
Mara G. Freire, ${ }^{a}$ Ana Rita R. Teles, ${ }^{a}$ Rute A. S. Ferreira, ${ }^{b}$ Luís D. Carlos, ${ }^{b}$ \\ José A. Lopes-da-Silva ${ }^{c}$ and João A. P. Coutinho*a \\ Received 30th July 2011, Accepted 18th August 2011 \\ DOI: 10.1039/c1gc15930e
}

Aiming at replacing the noxious solvents commonly employed, ionic-liquid-based solvents have been recently explored as novel non-volatile and non-flammable media for the electrospinning of polymers. In this work, nanosized and biodegradable cellulose fibers were obtained by electrospinning at room temperature using a pure ionic liquid or a binary mixture of two selected ionic liquids. The electrospinning of $8 \mathrm{wt} \%$ cellulose in 1-ethyl-3-methylimidazolium acetate medium (a low viscosity and room temperature ionic liquid capable of efficiently dissolving cellulose) showed to produce electrospun fibers with average diameters within $(470 \pm 110) \mathrm{nm}$. With the goal of tailoring the surface tension of the spinning dope, a surface active ionic liquid was further added in a 0.10:0.90 mole fraction ratio. Electrospun cellulose fibers from the binary mixture composed of 1-ethyl-3-methylimidazolium acetate and 1-decyl-3-methylimidazolium chloride ionic liquids presented average diameters within $(120 \pm 55) \mathrm{nm}$. Scanning electron microscopy, X-ray diffraction analysis, nuclear magnetic resonance spectroscopy, Fourier transform infrared spectroscopy, and thermogravimetric assays were used as core methods to evaluate the structural integrity, morphology and crystallinity of the raw, electrospun, and regenerated samples of cellulose. Moreover, the photoluminescence spectra of both raw and electrospun fibers were acquired, and compared, indicating that the cellulose emitting centers are not affected by the dissolution of cellulose in ionic liquids. Finally, the use of non-volatile solvents in electrospinning coupled to a water coagulation bath allows the recovery of the ionic fluid, and represents a step forward into the search of environmentally friendly alternatives to the conventional approaches.

\section{Introduction}

The declining resources of fossil fuels, as well as the global heating caused by greenhouse gas emissions, have become unquestionable threats. Both novel environmentally friendly processes and materials are being actively sought by companies and academic researchers in order to mitigate those critical concerns. Lignocellulosic materials are the most abundant renewable resource available. Their efficient and comprehensive utilization would provide a practical route capable of main-

a'Departamento de Química, CICECO, Universidade de Aveiro,

3810-193, Aveiro, Portugal. E-mail: jcoutinho@ua.pt;

Fax: +351-234-370084; Tel: +351-234-370200

${ }^{b}$ Physics Department, CICECO, Universidade de Aveiro, 3810-193,

Aveiro, Portugal

'QOPNA Unit, Departamento de Química, Universidade de Aveiro,

3810-193, Aveiro, Portugal

$\dagger$ Electronic supplementary information (ESI) available. See DOI: $10.1039 / \mathrm{clgc} 15930 \mathrm{e}$ taining a sustainable social development while reducing the dependence of long-established petroleum-based chemical and energy industries.

Cellulose is an important target for energy conversion and a major component of lignocellulosic sources. ${ }^{1}$ Its benign properties, namely biocompatibility, biodegradability, and regenerative properties, make cellulose an environmental friendly material. ${ }^{1}$ Cellulose fibers are nowadays being used as the basis of functionalized materials and fiber-reinforced composites. ${ }^{2,3}$ Fibers in the nanometre range display improved properties, such as high surface energy and glass transition temperatures, high thermal and electrical conductivities, and enhanced surface reactivity. ${ }^{4}$

Electrospinning is a method commonly used to prepare nanosized fibers driven by an external electric force applied to a polymer solution or melt. Electrospun fibers of cellulose have great potential in distinct applications, namely in membranes, biosensors, electronic and optical devices, as well as in enzyme and catalytic supports. ${ }^{5}$ The main fields making use 
of electrospun cellulose fibers are the pharmaceutical, textile and packaging industries. ${ }^{5}$ Their applications have also moved beyond into the scope of biomedicine. ${ }^{6-8}$

The intrinsic lack of solubility of native cellulose in water, and most organic solvents, constitutes a major obstacle for its proficient utilization. The complex molecular structure of cellulose imposes the main difficulties to its dissolution and effective electrospinning. Hence, the electrospinning of cellulose has typically relied on the use of cellulose derivatives, for instance, cellulose acetate. ${ }^{9}$ Electrospun cellulose fibers from its acetate derivatives have been obtained using the mixture acetone/dimethylformamide/trifluoroethylene as the main solvent, and subsequently regenerated by alkaline treatment. ${ }^{10}$ Yet, fibers obtained from cellulose derivatives are more susceptible to degradation and have reduced thermal stability when compared to native cellulose. Up to now, few non-derivatizing solvents have proved to be able of producing electrospun fibers from native cellulose: $\mathrm{N}$ methylmorpholine- $N$-oxide/water, ethylenediamine/potassium thiocyanate and $N, N$-dimethylacetamide/lithium chloride mixtures. ${ }^{11}$ Besides the non-volatile ionic species, the remaining solvents are toxic and noxious to the environment. The replacement of these solvents by others, more benign and environmentally friendly, would represent a major step towards the development of sustainable cellulose-based compounds.

Among new potential solvents for cellulosic biomaterials, ionic liquids (ILs) are attracting considerable attention. In 2002, Swatloski et al. ${ }^{12}$ were the first to report the effective dissolution of cellulose in ionic liquids. Ionic liquids have received the epithet of "green solvents" due to their unique characteristics, e.g., low melting points, negligible vapour pressures, general non-flammability, thermal stability, and recycling simplicity, among others. Moreover, they were shown to be non-derivatizing solvents for cellulose (with no covalent interactions involved) while it was demonstrated that solvation predominantly occurs by hydrogen bonding interactions between the sugar building blocks and the ionic liquid anion. ${ }^{13,14}$ As a result, the dissolution of cellulose in ionic liquids has provided a new platform for cellulose processing..$^{15,16}$ Further attempts showed that ionic liquid analogues can be formed by the addition of choline chloride derivatives and urea (or carboxylic acids) through the formation of eutectic mixtures, ${ }^{17,18}$ and that these mixtures were successful in the functionalization of cellulose. ${ }^{19}$

To the best of our knowledge, only four reports have dealt with the use of ionic liquids as solvents for cellulose electrospinning. ${ }^{20-22}$ Nonetheless, such works used a highly viscous ionic liquid, solid at room temperature and requiring high energy consumptions, ${ }^{20,21}$ or mixtures between an ionic liquid and hazardous organic solvents. ${ }^{22}$ Linhardt and coworkers ${ }^{20}$ prepared cellulose and cellulose-heparin composite fibers using the 1-butyl-3-methylimidazolium chloride and 1ethyl-3-methylimidazolium benzoate ionic liquids. In the same line of investigation, Quan et al. ${ }^{21}$ applied the same chloridebased ionic liquid for the dissolution of cellulose, and subsequent production of nonwoven cellulose fibers, through the modification of the electrospinning setup to operate at $373 \mathrm{~K}$. $\mathrm{Xu}$ et al $^{22}$ investigated the electrospinning of cellulose using 1- allyl-3-methylimidazolium chloride combined with a co-solvent, dimethyl sulfoxide, to reduce the surface tension, viscosity and entanglement density of the network, thus allowing a continuous jet. A more recent work ${ }^{23}$ has showed the production of coresheath multiwalled carbon nanotube-cellulose fibers using a coaxial electrospinning setup making use of a room temperature ionic liquid, 1-ethyl-3-methylimidazolium acetate. Multiwalled carbon nanotube-cellulose mats, having both a cable structure core (carbon nanotubes) and insulating sheath (cellulose), were obtained ${ }^{23}$ In addition, a recent work by Rogers and coworkers ${ }^{24}$ demonstrated the ability of producing lignocellulosic biomass composite fibers (southern yellow pine and bagasse) using the ionic liquid 1-ethyl-3-methylimidazolium acetate at temperatures above the glass transition temperature of lignin. Others attempts have been carried out aiming at electrospinning synthetic polymers using ionic liquids. ${ }^{25-29} \mathrm{~A}$ complete review on this topic was recently reported..$^{30}$

The number of unexplored ionic liquids that could be used as solvents for cellulose electrospinning, besides the mainly chloride-based ionic liquids previously investigated, ${ }^{20-22}$ undoubtedly opens a new path of opportunities. The possibility of tuning the physical/chemical properties of ionic liquids, and thus their solvation ability, may allow the tailoring and control of dissolution, processing and materials' final properties. Concomitantly, the successful application of ionic liquids in electrospinning could increase the number and types of biomaterials from which the fibers can be made.

In this context, the aim of this work is the production of nanosized cellulose fibers from electrospinning using nonvolatile ionic liquids as pure solvents while operating at room temperature. From the large array of possible ionic liquids, 1-ethyl-3-methylimidazolium acetate, $\left[\mathrm{C}_{2} \mathrm{mim}\right]\left[\mathrm{CH}_{3} \mathrm{CO}_{2}\right]$, was selected as the main solvent as a result of its desirable properties, namely low toxicity $\left(\mathrm{ED}_{50}=2860 \mathrm{mg} \mathrm{dm}^{-3}\right)$, low viscosity, low melting temperature $(<253 \mathrm{~K})$, low corrosiveness, favourable biodegradability and high cellulose dissolution capacity. ${ }^{13,14,31,32}$ The increased basicity of the acetate anion makes it more efficient at disrupting the intra- and intermolecular hydrogen bonding network in cellulose compared to chloride-based ionic liquids. ${ }^{13,14}$ Furthermore, the low viscosity and melting temperature of $\left[\mathrm{C}_{2} \mathrm{mim}\right]\left[\mathrm{CH}_{3} \mathrm{CO}_{2}\right]$ facilitate the dissolution, handling, and electrospinning of cellulose at temperatures near to room temperature. To further enhance the solvent thermophysical properties, in particular aiming at a reduction of the surface tension, a second and surface active ionic liquid (1-decyl-3-methylimidazolium chloride, $\left.\left[\mathrm{C}_{10} \mathrm{mim}\right] \mathrm{Cl}\right)^{33}$ was used as an additive (in a mole fraction ratio of 0.10 in respect to $\left.\left[\mathrm{C}_{2} \operatorname{mim}\right]\left[\mathrm{CH}_{3} \mathrm{CO}_{2}\right]\right)$, and the electrospinning of cellulose was further performed using the binary mixture of ionic liquids. Scanning electron microscopy (SEM), X-ray diffraction analysis, Nuclear Magnetic Resonance (NMR) spectroscopy, Fourier Transform Infrared (FTIR) spectroscopy, and thermogravimetric (TGA) assays were used as main methods to assess the structural integrity, morphology and crystallinity of the original, electrospun and regenerated samples of cellulose. Finally, to explore the viability of the electrospun fibers for applications in optical devices, their photoluminescence spectra were recorded at room temperature and compared to that of raw cellulose. 


\section{Results and discussion}

In contrast to the previous works ${ }^{20-22}$ dealing with the electrospinning of native cellulose from ionic liquids (either by the addition of volatile co-solvents or by operating the process at temperatures above the melting temperature of the chloride-based ionic liquids), in this work the electrospinning of pure cellulose was performed at room temperature $(\approx 298 \mathrm{~K})$ using low viscosity room temperature ionic liquids: 1-ethyl-3-methylimidazolium acetate which was used as the main solvent and 1-decyl-3methylimidazolium chloride which was used as an additional ionic liquid to control the surface tension of the doping solution. Cellulose solutions at $8 \mathrm{wt} \%$ were used in all experiments (after previous optimization tests). The electrospun cellulose fibers were collected in a water coagulation bath, and further washed with water and ethanol. Both ionic liquids are completely miscible with water affording the removal of the remnant ionic fluids from the cellulose fibers while allowing the reuse of the ionic liquids by simple evaporation of the molecular solvent.

In order to optimize the electrospun fibers diameter size and homogeneity, as well as the fibers morphology, two major parameters were evaluated: dissolution status of cellulose, and physicochemical properties related to the ionic liquid main solvent.

To evaluate the progress of cellulose dissolution ( $8 \mathrm{wt} \%$ ) in the ionic liquid at room temperature, periodical samples of the mixture were taken and analyzed through optical polarized microscopy. The presence of crystalline parts of cellulose indicates that the solubilization was not completely achieved (see ESI with the macroscopic and microscopic trend on the cellulose dissolution at different times of dissolution at $\approx 298 \mathrm{~K}$ ). Complete cellulose dissolution, under the agitation and temperature conditions employed, was achieved only after $72 \mathrm{~h}$ of homogenization. Electrospinning was further performed with the cellulose/[ $\mathrm{C}_{2}$ mim $]\left[\mathrm{CH}_{3} \mathrm{CO}_{2}\right]$ mixtures with $24 \mathrm{~h}, 48 \mathrm{~h}$, and $72 \mathrm{~h}$ of constant stirring to obtain a deeper insight on the dissolution status of cellulose on the morphology and size of electrospun fibers. SEM images (see ESI) show that the dissolution of cellulose at $72 \mathrm{~h}$ provides a higher homogeneity and lower size of the electrospun cellulose fibers. Therefore, the complete dissolution of cellulose showed to be a crucial condition for producing nanosized electrospun fibers. Fig. 1 depicts the structure, size and morphology of the electrospun fibers obtained from a $8 \mathrm{wt} \%$ polymer solution in $\left[\mathrm{C}_{2} \mathrm{mim}\right]\left[\mathrm{CH}_{3} \mathrm{CO}_{2}\right]$ after complete dissolution.

It is well accepted that the fiber diameter and morphology are mainly controlled by the adjustment of the solution physical properties and by electrospinning inherent parameters. The optimized operational conditions (electric field and spinning rate) and the choice of a low viscosity room temperature ionic liquid capable of efficiently dissolving cellulose showed to produce electrospun fibers with average diameters within $(470 \pm 110) \mathrm{nm}$, as depicted in Fig. 1 .

Previously it was demonstrated that an increase in the cellulose content leads to cellulose fibrils and avoids the formation of massive blocks. ${ }^{20}$ Moreover, the flow rate of the spinning solution has showed to be a critical factor in affecting the solidification of the cellulose fibers. ${ }^{20}$ In fact, the viscosities of solutions containing cellulose and chloride-based ionic liquids

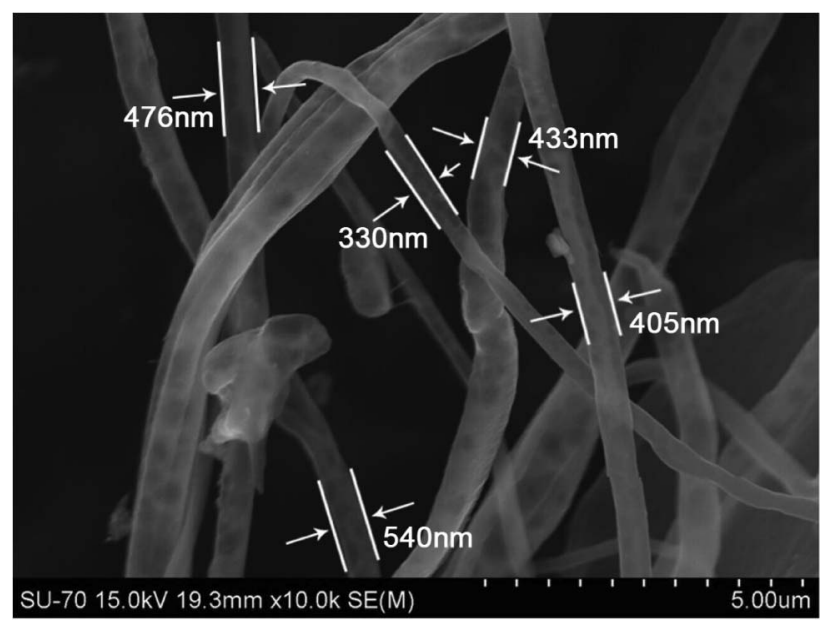

Fig. 1 SEM image of electrospun cellulose fibers from a $8 \mathrm{wt} \%$ polymer solution in $\left[\mathrm{C}_{2} \mathrm{mim}\right]\left[\mathrm{CH}_{3} \mathrm{CO}_{2}\right]$ (after complete dissolution achieved with $72 \mathrm{~h}$ of homogenization at $298 \mathrm{~K}$ ).

are several times higher than solutions composed of acetatebased ionic liquids and the same polymer. ${ }^{34}$ Hence, the selection of a highly conductive and low viscous solvent capable of solvating substantial amounts of cellulose $(8 \mathrm{wt} \%)$ seems to be one of the key features that led to the nanosized nonwoven fibers obtained here. Indeed, nanosized cellulose fibers obtained in this work are substantially smaller and more homogeneous than those previously reported..$^{20-22}$ Nevertheless, it should be remarked that the raw cellulose employed in this work presents a lower molecular weight compared to cellulose samples used in previous reports. ${ }^{20-22}$

The changes in the supermolecular structure of cellulose during regeneration steps are crucial issues with respect to the application of the polymer nanofibers. The crystallinity of the raw and electrospun cellulose were investigated through X-ray diffraction analysis. Besides, a cellulose casting film obtained from a straightforward regeneration of cellulose dissolved in the ionic liquid, and making use of water as anti-solvent, was also evaluated in order to examine the role of electrospinning in modifying the cellulose structure. The casting film was also submitted to further washing steps with water and ethanol to eliminate the residual ionic liquid solvent. X-Ray diffraction patterns are depicted in Fig. 2. Raw cellulose used for electrospinning was found to be of Type-I polymorph (characteristic peaks at $2 \theta=14.9^{\circ}, 16.3^{\circ}, 22.5^{\circ}$ and $\left.34.6^{\circ}\right){ }^{35}$ After the cellulose dissolution in the ionic liquid and subsequent regeneration, electrospun cellulose fibers and regenerated casting film are more amorphous with the remaining crystalline parts being polymorphs of Type-II with a characteristic peak at $2 \theta=20.8^{\circ} .^{35}$ The fast precipitation of cellulose from the ionic liquid solution with water is responsible for the poorer re-crystallization of the cellulose chains. Indeed, when cellulose has been solubilised and regenerated, the transformation of cellulose I to cellulose II will remain an irreversible accomplishment. This trend indicates that during the dissolution process, the ionic liquid destroys the intermolecular hydrogen bonding of cellulose and its lattice structure.

A higher degree of crystallinity is usually an indication of enhanced thermal properties. Therefore, the thermal stabilities 


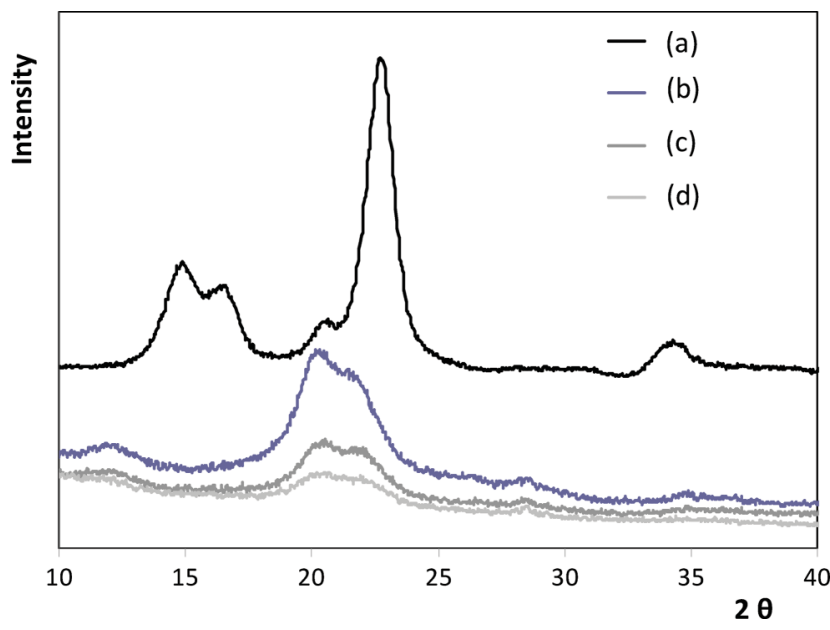

Fig. 2 X-Ray diffraction patterns of raw cellulose (a), regenerated casting film (b) and electrospun cellulose fibers from the neat $\left[\mathrm{C}_{2} \mathrm{mim}\right]\left[\mathrm{CH}_{3} \mathrm{CO}_{2}\right]$ (c), and from the $\left[\mathrm{C}_{2} \mathrm{mim}\right]\left[\mathrm{CH}_{3} \mathrm{CO}_{2}\right] /\left[\mathrm{C}_{10} \mathrm{mim}\right] \mathrm{Cl}$ mixture (d).

of the raw cellulose, regenerated cellulose film and electrospun cellulose fibers were also investigated. The TGA results are depicted in Fig. 3. The thermal stabilities of electrospun fibers are only slightly lower $(\approx 10 \mathrm{~K})$ than that of raw cellulose. Nevertheless, the degradation of the regenerated film occurs at significantly lower temperatures with a major weight reduction at circa $520 \mathrm{~K}$. As expected, the fibrillar morphology of electrospun fibers contributes to a higher thermal stability compared to the cellulose casting film.

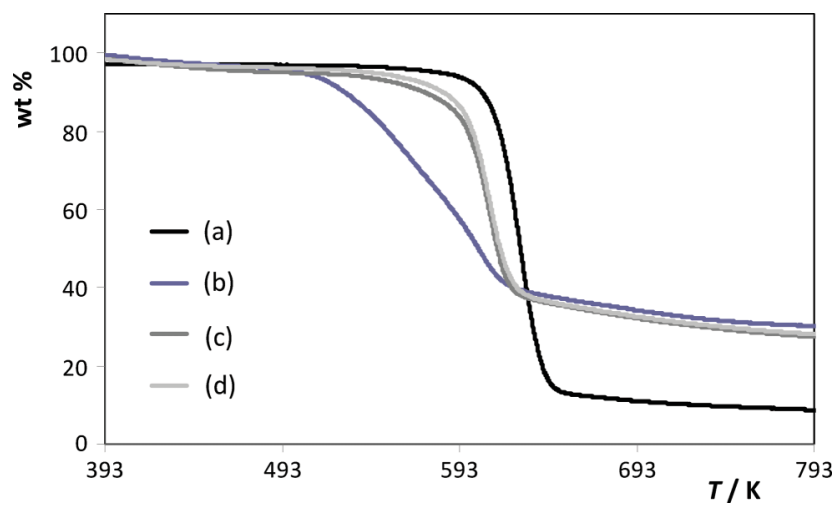

Fig. 3 TGA of raw cellulose (a), regenerated casting film (b) and electrospun cellulose fibers from the neat $\left[\mathrm{C}_{2} \mathrm{mim}\right]\left[\mathrm{CH}_{3} \mathrm{CO}_{2}\right]$ (c), and from the $\left[\mathrm{C}_{2} \mathrm{mim}\right]\left[\mathrm{CH}_{3} \mathrm{CO}_{2}\right] /\left[\mathrm{C}_{10} \mathrm{mim}\right] \mathrm{Cl}$ mixture (d).

In order to improve the electrospinnability of cellulose, by decreasing the surface tension and classical Rayleigh instability of the ionic medium, a surface active ionic liquid, ${ }^{33}\left[\mathrm{C}_{10} \mathrm{mim}\right] \mathrm{Cl}$, was added to the main solvent $\left[\mathrm{C}_{2} \mathrm{mim}\right]\left[\mathrm{CH}_{3} \mathrm{CO}_{2}\right]$. With the goal of selecting an adequate mole fraction ratio of both ionic liquids, measurements of surface tension and viscosity of $\left[\mathrm{C}_{2} \mathrm{mim}\right]\left[\mathrm{CH}_{3} \mathrm{CO}_{2}\right]-\left[\mathrm{C}_{10} \mathrm{mim}\right] \mathrm{Cl}$-containing mixtures were performed at $298 \mathrm{~K}$. Results for the surface tension and viscosity of the ionic liquid binary mixtures as a function of the mole fraction content of $\left[\mathrm{C}_{10} \mathrm{mim}\right] \mathrm{Cl}$ are sketched in Fig. 4 . The surface tension and viscosity values, as well as density values needed for the correction of surface tension, along the mole

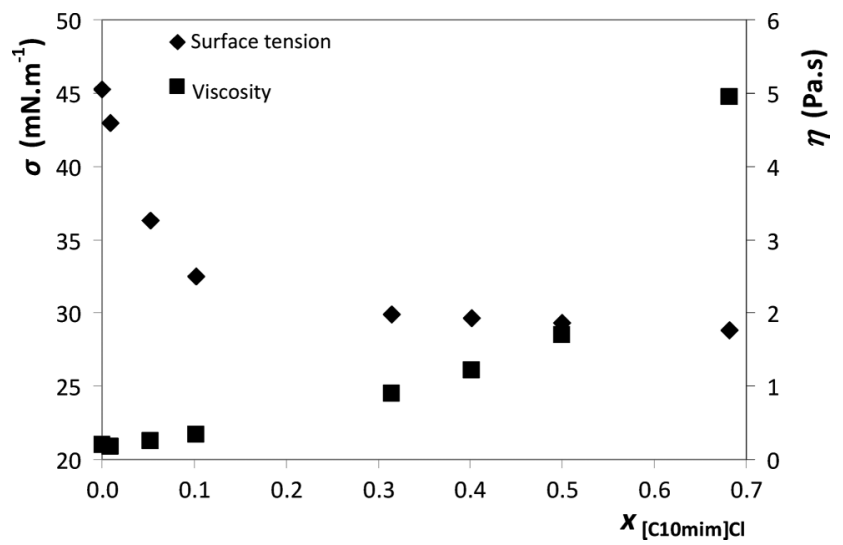

Fig. 4 Surface tension and apparent viscosity (at a shear rate of $2 \mathrm{~s}^{-1}$ ) of $\left[\mathrm{C}_{2} \mathrm{mim}\right]\left[\mathrm{CH}_{3} \mathrm{CO}_{2}\right] /\left[\mathrm{C}_{10} \mathrm{mim}\right] \mathrm{Cl}$ mixtures as a function of the mole fraction content of $\left[\mathrm{C}_{10} \mathrm{mim}\right] \mathrm{Cl}$ at $298 \mathrm{~K}$.

fraction ratio of the two ionic liquids, are presented in the ESI. Viscosity measurements of all binary mixtures of ionic liquids, and ionic liquid/cellulose mixtures, in a shear rate range from $0.02 \mathrm{~s}^{-1}$ to $600 \mathrm{~s}^{-1}$, were also determined and are provided in ESI.

The surface activity of $\left[\mathrm{C}_{10} \mathrm{mim}\right] \mathrm{Cl}$ in aqueous environments was previously reported. ${ }^{33}$ The pattern here obtained indicates that the long chain ionic liquid preferentially migrates for the vapour-liquid interface in a polar ionic medium and significantly decreases the surface tension of the mixture. On the other hand, the viscosity of pure $\left[\mathrm{C}_{10} \mathrm{mim}\right] \mathrm{Cl}$ is significantly higher than that presented by the acetate-based ionic liquid, and an increase in the mole fraction content of $\left[\mathrm{C}_{10} \mathrm{mim}\right] \mathrm{Cl}$ leads to a progressive increase in the viscosity of the binary mixture. Therefore, taking into account that the surface tensions decrease, while the viscosities increase, with the $\left[\mathrm{C}_{10} \mathrm{mim}\right] \mathrm{Cl}$ content, a careful selection of the binary mixture composition was considered. Due to the high viscosity of the longer alkyl chain ionic liquid and the trend in the surface tension decrease, the mole fraction ratio selected for further cellulose dissolution and electrospinning was that of 0.90 of $\left[\mathrm{C}_{2} \mathrm{mim}\right]\left[\mathrm{CH}_{3} \mathrm{CO}_{2}\right]$ and 0.10 of $\left[\mathrm{C}_{10} \mathrm{mim}\right] \mathrm{Cl}$. $\left[\mathrm{C}_{10} \mathrm{mim}\right] \mathrm{Cl}$ played a vital role, even at a mole fraction of 0.10 , by significantly decreasing the surface tension of the spinning dope (from 45.44 to $32.49 \mathrm{mN} \mathrm{m}^{-1}$ ) while only slightly increasing the viscosity (a bulk property and from 0.199 to $0.345 \mathrm{~Pa} \mathrm{~s}$ ) at this composition. Thus, this binary mixture was used to dissolve cellulose at $8 \mathrm{wt} \%$ and the aforementioned optimized operational conditions were used during the electrospinning process (the time of dissolution was kept at $72 \mathrm{~h}$ to afford a complete dissolution of cellulose in the mixture of ionic liquids).

It should be remarked that the addition of $8 \mathrm{wt} \%$ of cellulose to the binary mixture of ionic liquids noticeably increased the shear viscosity of the solution (see ESI). Nevertheless, the fluidity of such cellulose-containing solution allowed the electrospinning process with a regular solution fed of $0.002 \mathrm{~cm}^{3} \mathrm{~min}^{-1}$ and at room temperature.

A SEM image of the obtained nonwoven fibers using the mixture of ionic liquids as the solvent is shown in Fig. 5. Electrospun cellulose fibers from the binary mixture of ionic liquids presented average diameters within $(120 \pm 55) \mathrm{nm}$. Further SEM micrographs used for the fibers diameter quantification are provided in the ESI. Compared to the fibers obtained 


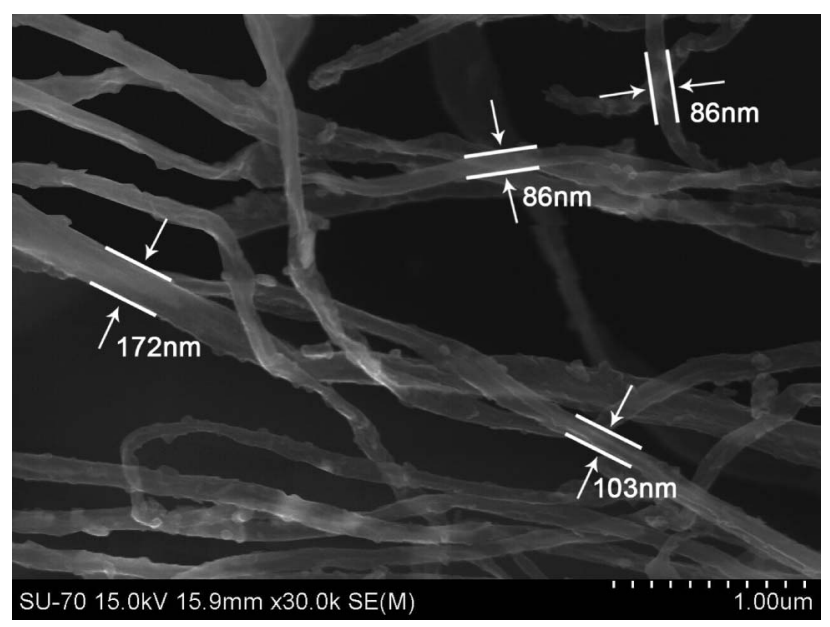

Fig. 5 SEM image of electrospun cellulose fibers from a $8 \mathrm{wt} \%$ polymer solution in $\left[\mathrm{C}_{2} \mathrm{mim}\right]\left[\mathrm{CH}_{3} \mathrm{CO}_{2}\right] /\left[\mathrm{C}_{10} \mathrm{mim}\right] \mathrm{Cl}$ (mole fraction ratio $0.90: 0.10$ ) (after complete dissolution achieved with $72 \mathrm{~h}$ of homogenization at $298 \mathrm{~K})$.

from the pure ionic liquid, smaller, and more homogeneous fibers were obtained. Therefore, the improved solvent properties contributed to a stabilization of the fibers morphology, as well as to a decrease in the fibers diameter, resulting in ultra-thin regenerated cellulose. Surface tensions of chloride-based ionic liquids ${ }^{22,35}$ previously used in the electrospinning of cellulose $\mathrm{e}^{20-22}$ range between $48.2 \mathrm{mN} \mathrm{m}^{-1}$ to $61.9 \mathrm{mN} \mathrm{m}^{-1}$ at temperatures close to room temperature, and thus, the reduction of the fibers size obtained in this work is also a result of the surface tension decrease in the overall polymeric solution.

From the inspection of Fig. 2, the electrospun cellulose fibers obtained from the binary mixture of ionic liquids are also a polymorph of Type-II. The transformation of cellulose Type-I into cellulose of Type-II was caused by the disruption of the inter- and intra-molecular hydrogen bonds during the dissolution in the ionic liquid medium.

Aiming at comparing the crystallinity of all cellulose samples, the crystallinity indices were determined from the X-ray difractograms based on the height ratio between the intensity of the crystalline peak $\left(I_{002}-I_{\mathrm{AM}}\right)$ and the total intensity $I_{002},{ }^{36}$ where $I_{002}$ is intensity of the crystalline peak when $2 \theta$ approximately equals $22^{\circ}$ and represents the diffraction intensity of crystallizing area, and $I_{\mathrm{Am}}$ is the intensity when $2 \theta$ is close to $18^{\circ}$ and that corresponds to the amorphous area of cellulose. In parallel with the X-ray difractograms, FTIR spectra (see ESI) were also used to provide crystallinity index comparisons. This relationship was originally proposed by O'Connor et al. ${ }^{37}$ that assigned the bands at the $1430 \mathrm{~cm}^{-1}$ and $893 \mathrm{~cm}^{-1}$ to crystalline and amorphous regions, respectively. Later on, Nelson and $\mathrm{O}^{\prime} \mathrm{Connor}^{38}$ proposed the use of the bands at $1372 \mathrm{~cm}^{-1}$ and $2900 \mathrm{~cm}^{-1}$, since the band at $2900 \mathrm{~cm}^{-1}$ does not changes with the lattice structure of cellulose and is commonly used as an internal standard for the determination of the cellulose crystallinity. This latter ratio proved to be consistent with X-ray diffraction trends obtained by further authors. ${ }^{23,39,40}$ In this work, both crystallinity indices were determined and are provided in Table 1. Both crystallinity indices, obtained from X-ray analysis and FTIR, are in close agreement and indicate that the crystallinity of cellulose decreases in the following rank: raw cellulose $>$ cellulose casting film > electrospun cellulose fibers obtained from the neat $\left[\mathrm{C}_{2} \mathrm{mim}\right]\left[\mathrm{CH}_{3} \mathrm{CO}_{2}\right]>$ electrospun cellulose fibers obtained from the $\left[\mathrm{C}_{2} \mathrm{mim}\right]\left[\mathrm{CH}_{3} \mathrm{CO}_{2}\right] /\left[\mathrm{C}_{10} \mathrm{mim}\right] \mathrm{Cl}$ mixture. However, it should be pointed out that yet the degree of crystallinity of the cellulose samples "treated" with ionic liquids is lower, it is still close to that shown by the raw cellulose. Although there is the conversion of cellulose Type-I to Type-II after the cellulose "treatment" with ionic liquids, the molecular ordering of cellulose in amorphous regions is still favoured.

The onset degradation temperature (Fig. 3) of the electrospun fibers obtained from the $\left[\mathrm{C}_{2} \mathrm{mim}\right]\left[\mathrm{CH}_{3} \mathrm{CO}_{2}\right]$ and $\left[\mathrm{C}_{10} \mathrm{mim}\right] \mathrm{Cl}$ mixture is similar to that verified previously with the electrospun fibers acquired from the isolated ionic liquid. In addition, both electrospun fibers obtained from different ionic liquid solutions are thermally more stable than the cellulose casting film. In addition, the weight loss percentage by TGA is shown to be dependent on the previous cellulose dissolution in ionic liquids. Cellulose samples that were previously dissolved in ionic liquids (both electrospun fibers and casting film) present a higher residual weight after the major loss degradation onset. However, a clear explanation of this fact was not found by us. Solid ${ }^{1} \mathrm{H}$ and ${ }^{13} \mathrm{C}$ NMR (in the ESI) and elemental analysis do not show further compounds or impurities in the "treated" cellulose. In this context, it seems that a more complex phenomenon, such as the polymerization of electrospun cellulose and casting film, is occurring at the higher temperatures. Similar results were reported by $\mathrm{Xu}$ et al. ${ }^{14}$ with TGA curves for original and regenerated cellulose from $\left[\mathrm{C}_{4} \mathrm{mim}\right]\left[\mathrm{CH}_{3} \mathrm{CO}_{2}\right] / \mathrm{LiCl}$ mixtures. The regenerated sample exhibited a slightly lower onset temperature for decomposition when compared to the raw cellulose, albeit giving a slightly higher char yield (non-volatile carbonaceous material) on pyrolysis indicated by the higher residual mass after the main decomposition step. ${ }^{14}$

Aiming at exploring the viability of the obtained electrospun fibers for optical applications, their photoluminescence spectra were also acquired. Fig. 6 compares the emission spectra of raw cellulose and of the electrospun nanofibers. Both samples display the common broad band in the green spectral region typical of cellulosic materials. ${ }^{41}$ Apart from a minor blue-shift in the emission energy peak position $(\sim 10 \mathrm{~nm})$ observed for the electrospun fibers, the emission spectra are indeed quite similar. The excitation spectra were monitored at $460 \mathrm{~nm}$,

Table 1 Crystallinity indices calculated from the X-ray diffractograms and FTIR spectra

\begin{tabular}{llc}
\hline Cellulose sample & $100 \times\left[\left(I_{002}-I_{\mathrm{AM}}\right) /\left(I_{002}\right)\right]$ & $A_{1372} / A_{2900}$ \\
\hline Raw cellulose & $A_{1433} / A_{897}$ & 79.40 \\
Regenerated casting film & 64.46 & 0.2556 \\
Electrospun cellulose fibers from the neat $\left[\mathrm{C}_{2} \mathrm{mim}\right]\left[\mathrm{CH}_{3} \mathrm{CO}_{2}\right]$ & 61.69 & 1.4528 \\
Electrospun cellulose fibers from the $\left[\mathrm{C}_{2} \mathrm{mim}\right]\left[\mathrm{CH}_{3} \mathrm{CO}_{2}\right] /\left[\mathrm{C}_{10} \mathrm{mim}\right] \mathrm{Cl}$ mixture & 58.56 & 1.4363 \\
\hline
\end{tabular}




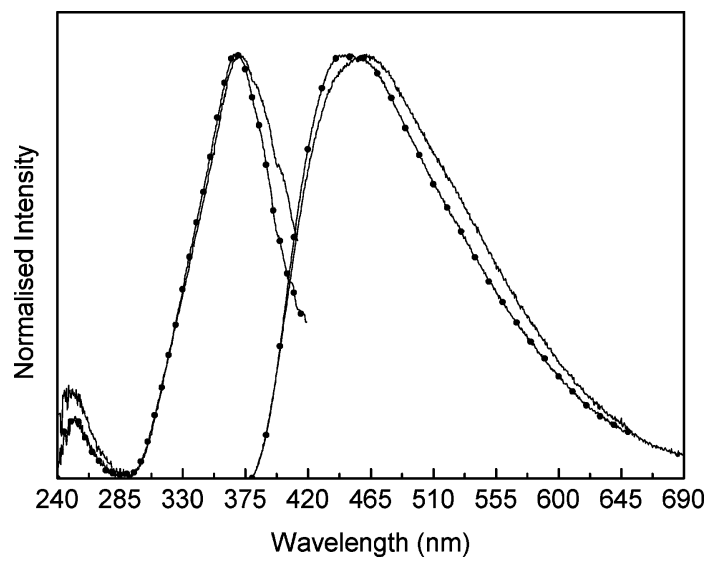

Fig. 6 Emission (right) and excitation (left) spectra of raw cellulose (solid lines) and of electrospun cellulose fibers from the neat $\left[\mathrm{C}_{2} \mathrm{mim}\right]\left[\mathrm{CH}_{3} \mathrm{CO}_{2}\right]$ (solid line and solid circles) excited at $360 \mathrm{~nm}$ and monitored at $460 \mathrm{~nm}$, respectively.

revealing for both materials a main band at $360 \mathrm{~nm}$ and a low-relative intensity peak at $250 \mathrm{~nm}$. Similarly to that found from the emission spectra, minor changes were detected when comparing the raw cellulose with the electrospun nanofibers. In particular, it is observed a small decrease $(\sim 10 \%)$ of the intensity of the band at $\sim 250 \mathrm{~nm}$ and in the full width at half maximum for the nanofibers when compared with that found for the raw polymer. The absolute emission quantum yield of both materials is below $0.01 \%$ (detection limit of the equipment). In order to further compare the impact of the processing method on the photoluminescence features of cellulose, the emission decay curves were also monitored (see ESI). The data are well reproduced by a single exponential function yielding to lifetime values of $8.66 \pm 0.12 \mathrm{~ns}$ and $7.20 \pm 0.17 \mathrm{~ns}$, for raw cellulose and electrospun nanofibers, respectively. The similarity between all the excitation and emission spectra, and decay curves, points out that the fabrication of nonwoven nanosized cellulose fibers by electrospinning keeps essentially unaffected the cellulose intrinsic emitting centers - and optical applications of the nanofibers are directly envisaged.

\section{Conclusions}

Typically electrospinning involves the evaporation of an organic solvent from the solution to produce polymer fibers. These polymer solutions often make use of noxious solvents, and release high levels of harmful compounds to the environment, that are difficult to be recovered and recycled. In this work, nonwoven nanosized cellulose fibers were obtained by electrospinning, at room temperature, using a pure non-volatile ionic liquid: $\left[\mathrm{C}_{2} \mathrm{mim}\right]\left[\mathrm{CH}_{3} \mathrm{CO}_{2}\right]$. Furthermore, the addition of a surface active room temperature ionic liquid $\left(\left[\mathrm{C}_{10} \mathrm{mim}\right] \mathrm{Cl}\right)$ to the $\left[\mathrm{C}_{2} \mathrm{mim}\right]\left[\mathrm{CH}_{3} \mathrm{CO}_{2}\right]$ yielded improved ultrafine cellulose fibers afforded by a careful manipulation of the solvent thermophysical properties. Moreover, the cellulose intrinsic emitting centers are not affected by the dissolution in ionic liquids. Cellulose was selected as a model biopolymer; yet, using the approach described in this work, the fabrication of a wide array of advanced functional biopolymer fibers and composites is directly envisaged.

\section{Experimental section}

\section{Materials}

Raw cellulose fibers $\left(M_{\mathrm{w}}=53000\right)$ (CAS 9004-34-6, SigmaAldrich) were dried in an air oven at $378 \mathrm{~K}$ for at least $12 \mathrm{~h}$ before use. The maximum water content of raw cellulose after the drying procedure was found to be $6.5 \mathrm{wt} \%$. A SEM image of the raw cellulose is depicted in the ESI. The ionic liquids used for electrospinning purposes, 1-ethyl-3methylimidazolium acetate, $\left[\mathrm{C}_{2} \mathrm{mim}\right]\left[\mathrm{CH}_{3} \mathrm{CO}_{2}\right]$ ( $>95 \mathrm{wt} \%$ pure), and 1-decyl-3-methylimidazolium chloride, $\left[\mathrm{C}_{10} \mathrm{mim}\right] \mathrm{Cl}(>98$ $\mathrm{wt}^{\circ} \%$ pure), were acquired from Iolitec. Additional ionic liquids used for the validation of surface tension measurements, viz. 1-butyl-3-methylimidazolium tetrafluoroborate, [ $\left.\mathrm{C}_{4} \mathrm{mim}\right]$ $\left[\mathrm{BF}_{4}\right]$ (>99 wt $\%$ pure), 1-butyl-3-methylimida-zolium bis(trifluoromethylsulfonyl)imide, $\left[\mathrm{C}_{4} \mathrm{mim}\right]\left[\mathrm{NTf}_{2}\right]$ (>99 $\mathrm{wt} \%$ pure), 1-butyl-3-octylimidazolium tetrafluoroborate $\left[\mathrm{C}_{8} \mathrm{mim}\right]\left[\mathrm{BF}_{4}\right]$ (>99 wt $\%$ pure), 1-butyl-3-octylimidazolium hexafluorophosphate, $\left[\mathrm{C}_{8} \mathrm{mim}\right]\left[\mathrm{PF}_{6}\right](>99 \quad \mathrm{wt} \%$ pure) and 1-butyl3-octylimidazolium bis(trifluoromethylsulfonyl)imide, $\left[\mathrm{C}_{8} \mathrm{mim}\right]\left[\mathrm{NTf}_{2}\right]$ (>99 wt \% pure), were purchased from IoLiTec. All ionic liquid samples were dried under vacuum, at constant stirring, and at $333 \mathrm{~K}$ for a minimum of $48 \mathrm{~h}$ before use. The ionic liquids purity was confirmed by ${ }^{1} \mathrm{H},{ }^{13} \mathrm{C}$ and ${ }^{19} \mathrm{~F}$ NMR spectroscopy after the drying procedure. The maximum water contents in all ionic liquid samples used both in electrospinning and in their thermophysical characterization are displayed in the ESI. In general, the water content of $\left[\mathrm{C}_{2} \mathrm{mim}\right]\left[\mathrm{CH}_{3} \mathrm{CO}_{2}\right]$ and $\left[\mathrm{C}_{10} \mathrm{mim}\right] \mathrm{Cl}$ used in electrospinning was maintained below $0.3 \mathrm{wt}^{\mathrm{O}} \%$.

The solvent used on the coulometric Karl Fischer titration was Hydranal-Coulomat AG from Riedel de Haën.

\section{Methods}

Water contents of the cellulose sample and ionic liquids were determined using a Metrohm 831 Karl-Fischer (KF) coulometer.

The molecular weight of cellulose was determined using the Mark-Houwink approach. ${ }^{41}$ Viscosimetric measurements were carried out using a capillary Ostwald viscometer at $298.15 \mathrm{~K}$. The intrinsic viscosity of raw cellulose was determined by a progressive dilution series in cupriethylenediamine solution (copper(II) ethylenediamine reagent RE from Panreac). The cellulose concentration ranged between (0.004 and 0.0008) $\mathrm{g} \mathrm{cm}^{-3}$. The molecular weight of cellulose was determined accordingly to eqn (1):

$$
[\eta]=M Q^{a}
$$

where $\eta$ is the intrinsic viscosity, $M$ is the molecular weight, and $Q$ and $a$ are constant values that depend on degree of polymerization of the polymer (in this work, $[\eta]=139.75 \mathrm{~cm}^{3}$ $\mathrm{g}^{-1}, Q=0.0026$, and $\left.a=1\right){ }^{42}$ Cellulose solutions at $8 \mathrm{wt}^{\%} \%$ in $\left[\mathrm{C}_{2} \mathrm{mim}\right]\left[\mathrm{CH}_{3} \mathrm{CO}_{2}\right]$ or in the $\left[\mathrm{C}_{2} \mathrm{mim}\right]\left[\mathrm{CH}_{3} \mathrm{CO}_{2}\right] /\left[\mathrm{C}_{10} \mathrm{mim}\right] \mathrm{Cl}$ mixture were prepared gravimetrically $\left( \pm 10^{-4} \mathrm{~g}\right)$, followed by stirring in sealed glass vials, and at $\approx 298 \mathrm{~K}$.

In order to evaluate the progress of cellulose dissolution, periodical samples of the mixture were taken, and analyzed through optical polarized microscopy making use of an Olympus BX51 microscope. 
The electrospinning equipment used in the study is a labmade apparatus composed by the following components: syringe pump Harvard Apparatus PHD 2000, with support for two syringes and infuse rate control between $0.0001 \mathrm{~mm}^{3} \mathrm{~min}^{-1}$ and $220.82 \mathrm{~cm}^{3} \mathrm{~min}^{-1}$; and an high voltage source Spellman CZE1000R, with a potential difference between 0 and $30 \mathrm{kV}$ and continues electric current between 0 and $300 \mu \mathrm{A}$. Further details concerning the lab-made electrospinning set up are described in literature. ${ }^{43}$

Each cellulose/ionic liquid mixture $(3 \mathrm{~g})$ was placed into a $5 \mathrm{~cm}^{3}$ syringe with a capillary tip with an inner diameter of $1 \mathrm{~mm}$. The syringe was maintained at a horizontal position while the syringe pump allowed a regular solution fed $\left(0.002 \mathrm{~cm}^{3} \mathrm{~min}^{-1}\right)$ through the needle. The applied voltage was maintained at $20 \mathrm{kV}$ and the tip-to-collector distance was fixed at $12 \mathrm{~cm}$ (in height). Previous operational optimization tests were performed through the macroscopic analysis of the Taylor cone and jet deposition to define these conditions.

A water bath under constant agitation, with an immersed copper electrode, was used as the grounded conductive collector. Water allowed the removal of ionic liquids from the cellulose fibers. This step is very important since an incomplete removal of the solvent can lead to polymer plasticization and to partial or complete fiber fusion. It should be remarked that the water bath allows the recovery of the ionic liquid by simple evaporation of the volatile solvent. The temperature of the electrospinning process was kept at $\approx(298 \pm 1) \mathrm{K}$. After the electrospinning course, cellulose fibers were collected and further immersed in ethanol for $24 \mathrm{~h}$, under constant stirring, and then repetitively washed with water and ethanol until no ionic liquid was found in the solvent by ${ }^{1} \mathrm{H}$ and ${ }^{13} \mathrm{C}$ NMR spectroscopic analysis. Moreover, the Fourier Transform Infrared (FTIR) spectra of the electrospun fibers do not display detectable traces of the acetate anion while scanning electron microscope (SEM) and field emission gun SEM (FESEM/EDS) analysis did not show the presence of nitrogen (that could be derived from the ionic liquid cation) (see ESI).

After the washing procedure to remove ionic liquid traces, electrospun cellulose fibers were placed into a vacuum oven at $298 \mathrm{~K}$ for a minimum of $24 \mathrm{~h}$ to dry off the molecular solvent.

SEM, using a Hitachi SU-70 microscope (after a carbon sputtering to afford a conductive film), was used to evaluate the morphology and size of the electrospun fibers. The field emission gun SEM (FESEM-ED) analyses were performed in a SU-70 UHR Schottky FESEM of Hitachi with a Quantax 400 EDS system of Bruker AXS (XFlash Silicon Drift Detector). It was applied a $15 \mathrm{kV}$ acceleration voltage and a current intensity of $32 \mu \mathrm{A}$.

TGA assays were performed with a SETSYS Evolution 1750 analyzer, from Setaram Instrumentation. Samples were heated at a constant rate of $10 \mathrm{~K} \mathrm{~min}^{-1}$ from $293 \mathrm{~K}$ up to $1073 \mathrm{~K}$, under a nitrogen flow of $200 \mathrm{~cm}^{3} \mathrm{~min}^{-1}$.

X-Ray diffractograms were recorded by monitoring the diffraction angle $2 \theta$ from $5^{\circ}$ to $55^{\circ}$ with a step-width of 0.040 under $\mathrm{Cu}-\mathrm{K} \alpha$ radiation source $(\lambda=0.15406 \mathrm{~nm})$ operating at $40 \mathrm{kV}$ and $40 \mathrm{~mA}$, and were obtained using a high resolution $\mathrm{X}$ ray diffraction analysis (HD-XRD Scan) with a Philips X'Pert diffractometer equipment.

The FTIR spectra, with a resolution of $4 \mathrm{~cm}^{-1}$, were obtained using a Perkin Elmer BX spectrometer operating in the at- tenuated total reflection (ATR) mode (equipped with a single horizontal Golden Gate ATR cell).

Surface tensions of pure ionic liquids and ionic liquids mixtures were determined using a Dataphysics contact angle system OCA-20, while rheological measurements were carried out on a controlled stress rheometer AR-1000 (TA instruments) with a cone-and-plate geometry $\left(4 \mathrm{~cm}\right.$ diameter, $\left.2^{\circ}\right)$. $\left[\mathrm{C}_{2} \mathrm{mim}\right]\left[\mathrm{CH}_{3} \mathrm{CO}_{2}\right] /\left[\mathrm{C}_{10} \mathrm{mim}\right] \mathrm{Cl}$ mixtures were prepared gravimetrically within $\pm 10^{-4} \mathrm{~g}$. Surface tensions were determined at $298.2 \mathrm{~K}$. The mole fraction composition of $\left[\mathrm{C}_{2} \mathrm{mim}\right]\left[\mathrm{CH}_{3} \mathrm{CO}_{2}\right]$ ranged between 1.00 and 0.30 . At least five independent measurements were carried out for each sample. The methodology and equipment used were properly validated measuring surface tensions for pure ionic liquids $\left(\left[\mathrm{C}_{4} \mathrm{mim}\right]\left[\mathrm{BF}_{4}\right],\left[\mathrm{C}_{4} \mathrm{mim}\right]\left[\mathrm{NTf}_{2}\right]\right.$, $\left[\mathrm{C}_{8} \mathrm{mim}\right]\left[\mathrm{BF}_{4}\right],\left[\mathrm{C}_{8} \mathrm{mim}\right]\left[\mathrm{PF}_{6}\right]$ and $\left.\left[\mathrm{C}_{8} \mathrm{mim}\right]\left[\mathrm{NTf}_{2}\right]\right)$ well established in literature ${ }^{44,45}$-results presented in the ESI. Since density data is required to correct surface tension values, the densities of the mixtures at $298.15 \mathrm{~K}$ were also determined using a using an automated SVM 3000 Anton Paar rotational Stabinger viscometer-densimeter. Further details regarding the operation system, as well as the respective validation, can be found elsewhere. ${ }^{46-48}$

${ }^{1} \mathrm{H}$ and ${ }^{13} \mathrm{C}$ NMR spectra were recorded on a $9.4 \mathrm{~T}$ WB Bruker Avance III spectrometer. A $4 \mathrm{~mm}$ double-resonance MAS probe was employed at $400.1\left({ }^{1} \mathrm{H}\right) / 100.6 \mathrm{MHz}\left({ }^{13} \mathrm{C}\right)$ Larmor frequencies, respectively. Chemical shifts are quoted in parts per million ( $\mathrm{ppm}$ ) and were calibrated with respect to the external reference, using TMS $\left({ }^{1} \mathrm{H}(\mathrm{TMS})=0 \mathrm{ppm}\right)$ and glycine powder $\left({ }^{13} \mathrm{C}(\mathrm{C}=\mathrm{O})=176.03 \mathrm{ppm}\right)$. For ${ }^{13} \mathrm{C} \mathrm{CP} / \mathrm{MAS}$ NMR a ramped cross-polarization $(\mathrm{CP})$ shaped pulse (varying from $100 \%$ to $50 \%$ in amplitude using 100 points) of $1.5 \mathrm{~ms}$ contact time was used to transfer spin magnetization from ${ }^{1} \mathrm{H}$ to ${ }^{13} \mathrm{C}$ nuclei. The ${ }^{1} \mathrm{H} 90^{\circ}$ excitation pulse was set to $4.1 \mu$ s employing a RF field strength of $61 \mathrm{kHz}$. For optimum CP transfer at a spinning rate of $v_{\mathrm{R}}=9.0 \mathrm{kHz}$, the ${ }^{1} \mathrm{H}$ and ${ }^{13} \mathrm{C} \mathrm{RF}$ field strength were set to 75 and $93 \mathrm{kHz}$, respectively (the Hartmann-Hahn matching condition was set to the first sideband $n= \pm 1$ ). CW decoupling was employed to achieve optimum ${ }^{1} \mathrm{H}$ heteronuclear decoupling during acquisition with a ${ }^{1} \mathrm{H}$ RF field strength of $60 \mathrm{kHz}$. A recycle delay of $5 \mathrm{~s}$ was used to acquire the $\mathrm{CP}$ experiments. For ${ }^{1} \mathrm{H}$ MAS/NMR the ${ }^{1} \mathrm{H} 90^{\circ}$ excitation pulse was set to $3.0 \mu \mathrm{s}$ using a RF field strength of $83 \mathrm{kHz}$. The spectra were acquired at a spinning rate of $15 \mathrm{kHz}$ using a recycle delay of $5 \mathrm{~s}$.

The photoluminescence spectra were recorded at room temperature with a modular double grating excitation spectrofluorimeter with a TRIAX 320 emission monochromator (Fluorolog-3 ${ }^{\circledR}$ 2-Triax, Horiba Scientific) coupled to a R928 Hamamatsu photomultiplier, using the front face acquisition mode. The excitation source was a $450 \mathrm{~W}$ Xe arc lamp. The emission spectra were corrected for detection and optical spectral response of the spectrofluorimeter and the excitation spectra were weighed for the spectral distribution of the lamp intensity using a photodiode reference detector. The room temperature emission decay curves were recorded on a spectrofluorometer (Fluorolog TCSPC, Horiba Scientific) coupled to a TBX-04 photomultiplier tube module $(950 \mathrm{~V}), 200 \mathrm{~ns}$ time-to-amplitude converter. The exciting source was a Horiba-Jobin-Yvon pulsed diode (NanoLED-330, peak at $330 \mathrm{~nm}, 1.2 \mathrm{~ns}$ pulse duration, 
$1 \mathrm{MHz}$ repetition rate, and $150 \mathrm{~ns}$ synchronization delay). The experimental excitation pulse was measured using a LUDOX scattering solution in water. The absolute emission quantum yields were measured at room temperature using a quantum yield measurement system C9920-02 from Hamamatsu with a $150 \mathrm{~W}$ xenon lamp coupled to a monochromator for wavelength discrimination, an integrating sphere as sample chamber and a multichannel analyser for signal detection. Three measurements were made for each sample so that the average value is reported. The method is accurate to within $10 \%$.

\section{Acknowledgements}

The authors are grateful to Fundação para a Ciência e a Tecnologia, SFRH/BPD/41781/2007, through the pos-doctoral scholarship of M.G. Freire, and project REEQ/515/CTM/2005. The authors also acknowledge the Portuguese National NMR Network (RNRMN), supported with funds from Fundação para a Ciência e a Tecnologia.

\section{References}

1 D. Klemm, B. Heublein, H. Fink and A. Bohn, Angew. Chem., Int. Ed., 2005, 44, 3358-3393.

2 A. K. Mohanty, M. Misra and L. T. Drzal, Natural fibers, biopolymers, and biocomposites, Taylor \& Francis, New York, 2005.

3 C. Baillie, Green composites: polymer composites and the environment, Woodhead Pub., Cambridge, 2004.

4 R. Vasita and D. S. Katti, Int. J. Nanomed., 2006, 1, 15-30.

5 P. Lu and B. Ding, Recent Pat. Nanotechnol., 2008, 2, 169-182.

6 J. D. Schiffman and C. L. Schauer, Polym. Rev., 2008, 48, 317-352.

7 D. Liang, B. S. Hsiao and B. Chu, Adv. Drug Delivery Rev., 2007, 59, 1392-1412.

8 K. Yoon, B. S. Hsiao and B. Chu, J. Mater. Chem., 2008, 18, 53265334.

9 K. Y. Lee, L. Jeong, Y. O. Kang, S. J. Lee and W. H. Park, Adv. Drug Delivery Rev., 2009, 61, 1020-1032.

10 Z. Ma, M. Kotaki and S. Ramakrishna, J. Membr. Sci., 2005, 265, $115-123$.

11 M. W. Frey, Polym. Rev., 2008, 48, 378-391.

12 R. P. Swatloski, S. K. Spear, J. D. Holbrey and R. D. Rogers, J. Am. Chem. Soc., 2002, 124, 4974-4975.

13 R. C. Remsing, R. P. Swatloski, R. D. Rogers and G. Moyna, Chem. Commun., 2006, 1271-1273.

14 A. Xu, J. Wang and H. Wang, Green Chem., 2010, 12, 268-275.

15 L. C. Tomé, M. G. Freire, L. P. N. Rebelo, A. J. D. Silvestre, C. Pascoal Neto, I. M. Marrucho and C. S. R. Freire, Green Chem., 2011, 13, 2464.

16 Y. Fukaya, K. Hayashi, M. Wada and H. Ohno, Green Chem., 2008, 10, $44-46$.

17 A. P. Abbott, G. Capper, D. L. Davies, R. K. Rasheed and V. Tambyrajah, Chem. Commun., 2003, 70-71.

18 A. P. Abbott, D. Boothby, G. Capper, D. L. Davies and R. K. Rasheed, J. Am. Chem. Soc., 2004, 126, 9142-9147.

19 A. P. Abbott, T. J. Bell, S. Handa and B. Stoddart, Green Chem., $2006,8,784-786$.
20 G. Viswanathan, S. Murugesan, V. Pushparaj, O. Nalamasu, P. M Ajayan and R. J. Linhardt, Biomacromolecules, 2006, 7, 415-418.

21 S.-L. Quan, S.-G. Kan and I.-J. Chin, Cellulose, 2009, 17, $223-$ 230.

22 S. Xu, J. Zhang, A. He, J. Li, H. Zhang and C. C. Han, Polymer, 2008, 49, 2911-2917.

23 M. Miyauchi, J. Miao, T. J. Simmons, J.-W. Lee, T. V. Doherty, J. S. Dordick and R. J. Linhardt, Biomacromolecules, 2010, 11, 24402445.

24 N. Sung, W. Li, B. Stoner, X. Jiang, X. Lu and R. D. Rogers, Green Chem., 2011, 13, 1158.

25 T. Zhao, H. Wang, Y. Zhang, B. Wang and J. Jiang, Int. J. Mol. Sci., 2007, 8, 680-685.

26 T. Yang, Y. Yao, Y. Lin, B. Wang, R. Xiang, Y. Wu and D. Wu, Appl. Phys. A: Mater. Sci. Process., 2009, 98, 517-523.

27 W. Yang, H. Yu, M. Zhu, H. Bai and Y. Chen, J. Macromol. Sci., Part B: Phys., 2006, 45, 573-579.

28 J. M. Seo, G. K. Arumugan, S. Khan and P. A. Heiden, Macromol. Mater. Eng., 2009, 294, 2755-2761.

29 X. Lu, J. Zhou, Y. Qiu and J. Li, Chem. Mater., 2008, 20, 3420-3424.

30 L. Meli, J. Miao, J. S. Dordick and R. J. Linhardt, Green Chem., 2010, 12, 1883-1892.

31 UFT Merck Ionic Liquids Biological Effects Database at http://www.il-eco.uft.uni-bremen.de/.

32 N. Sun, M. Rahman, Y. Qin, M. L. Maxim, H. Rodríguez and R. D. Rogers, Green Chem., 2009, 11, 646-655.

33 M. Blesic, M. H. Marques, N. V. Plechkova, K. R. Seddon, L. P. N. Rebelo and A. Lopes, Green Chem., 2007, 9, 481-490.

34 R. Sescousse, K. A. Le, M. E. Ries and T. Budtova, J. Phys. Chem. $B, 2010,114,7222-7228$.

35 M. H. Ghatee and A. R. Zolghadr, Fluid Phase Equilib., 2008, 263, $168-175$.

36 L. Segal, J. J. Creely, A. E. Martin Jr. and C. M. Conrad, Text. Res. J., 1959, 29, 786-794.

37 R. T. O'Connor, E. F. DuPre and D. Mitchum, Text. Res. J., 1958, 28, 382-392.

38 M. L. Nelson and R. T. O’Connor, J. Polymer Sci., 1964, 8, 1325 1341.

39 N. Wistara, X. Zhang and R. A. Young, Cellulose, 1999, 6, 325-348.

40 W. L. E. Magalhães, X. Cao and L. A. Lucia, Langmuir, 2009, 25, 13250-13257.

41 M. Z. Gavrilov and I. N. Ermolenko, J. Appl. Spectrosc., 1966, 5, $542-544$.

42 Scandinavian Pulp, Paper and Board-Testing Committee, PulpsViscosity in cupri-ethylenediamine solution, SCAN-CM 15:88, revised in 1988.

43 J. A. Lopes-da-Silva, B. Veleirinho and I. Delgadillo, J. Nanosci. Nanotechnol., 2009, 9, 3798-3804.

44 M. G. Freire, P. J. Carvalho, A. M. Fernandes, I. M. Marrucho, A. J. Queimada and J. A. P. Coutinho, J. Colloid Interface Sci., 2007, 314, 621-630.

45 P. J. Carvalho, M. G. Freire, I. M. Marrucho, A. J. Queimada and J. A. P. Coutinho, J. Chem. Eng. Data, 2008, 53, 1346-1350.

46 F. S. Oliveira, M. G. Freire, P. J. Carvalho, J. A. P. Coutinho, J. N. Canongia Lopes, L. P. N. Rebelo and I. M. Marrucho, J. Chem. Eng. Data, 2010, 55, 4514-4520.

47 C. M. S. S. Neves, M. L. S. Batista, A. F. M. Cláudio, L. M. N. B. F. Santos, I. M. Marrucho, M. G. Freire and J. A. P. Coutinho, J. Chem. Eng. Data, 2010, 55, 5065-5073.

48 C. M. S. S. Neves, P. J. Carvalho, M. G. Freire and J. A. P. Coutinho, J. Chem. Thermodyn., 2011, 43, 948-957. 